\title{
Sensitivity analysis of a morphodynamic modeling system applied to a Portuguese tidal inlet
}

\author{
X. Bertin, A.B. Fortunato \& A. Oliveira \\ Estuaries and Coastal Zones Division, National Civil Engineering Laboratory, Lisbon, Portugal
}

\begin{abstract}
Coastal area morphodynamic models are prone to severe errors arising from various sources, including: (1) the use of empirical sediment transport formulae (Pinto et al., 2006); (2) the reliability of the data used to feed the models; (3) the use of simplifying physical assumptions; (4) the error propagation between the various modules. Since these errors can be significant, the usefulness and credibility of morphodynamic simulations require a thorough understanding of their uncertainty. This paper addresses the practical implications of these input parameters on the development of a tidal inlet. A sensitivity analysis is performed through the application of the morphodynamic modeling system MORSYS2D (Fortunato and Oliveira, 2004) to the Óbidos lagoon (Oliveira et al., 2005), a small but very rapidly evolving coastal system located in western Portugal. The influences of: (1) sediment characteristics; (2) the choice of the forcing tide and (3) the sediment transport formula are analysed, namely through the inlet cross-section evolution and the ebb-delta development. The choice of the forcing tide appears important, since the use of a real tide, rather than a representative tide, induces: (1) faster morphological changes; (2) 15-day cyclic evolutions (spring-neap tidal cycle); (3) larger ebb-deltas and inlet cross-sections. Sediment grain size and empirical transport formulae rather affect the rapidity of morphological changes, since equilibrium is reached after 3 months of simulations and final inlet morphologies are noticeably comparable. Nevertheless, the good agreement of the results after three months of simulation demonstrates the reliability of the modelling system on the time scales of months.
\end{abstract}

\section{INTRODUCTION}

The economical and environmental importance of tidal inlets has been growing worldwide for the last decades. The management of these coastal systems is no longer restricted to the maintenance of navigation channels but also addresses new challenges such as adjacent shoreline stabilization or water renewal in the back barrier lagoons which are often used for aquaculture. Portuguese inlets illustrate this fact very well, since they often combine: (1) construction development on the barrier islands, (2) aquaculture and fishing; (3) commercial maritime traffic; (4) tourism and recreational activities. Because of the combination of a meso-tidal range with a severe wave climate, Portuguese tidal inlets are often characterized by fast and complex dynamics. Therefore, it appears essential to understand and to predict bathymetric changes of these coastal systems in the perspective of their sustainable development.

To reach this goal, the development of reliable morphodynamic modeling systems appears one of the most promising avenues. These modeling systems are typically composed of different coupled modules, which reproduce water flows, wave propagation, sediment transport and bottom evolution. The strongly non-linear coupling between these modules generate numerical oscillations and instabilities, that have started to be addressed in the last years, by using numerical filters (Johnson and Ziserman, 2002; Callaghan et al., 2006), by introducing artificial diffusion in the Exner equation (Cayocca, 2001) or by improving time-marshing schemes (Thanguy et al., 1993). In addition to these numerical problems, the computation of sand fluxes itself has limitations due to errors of the empirical transport formulae, the data used to feed these formulae (Pinto et al., 2006), and the propagation of these errors through the various modules (Fortunato, 2007).

Given these various potential error sources, performing a sensitivity analysis when using a given morphodynamic modeling system appears essential before envisaging obtaining reliable morphological predictions. It is the purpose of this paper to perform such a sensitivity analysis, through the application of the MORSYS2D modeling system (Fortunato and Oliveira, 2004, 2007a) to the very rapidly evolving Óbidos Lagoon, located on the western Coast of Portugal. This coastal system will be briefly described in the following section. The modeling 

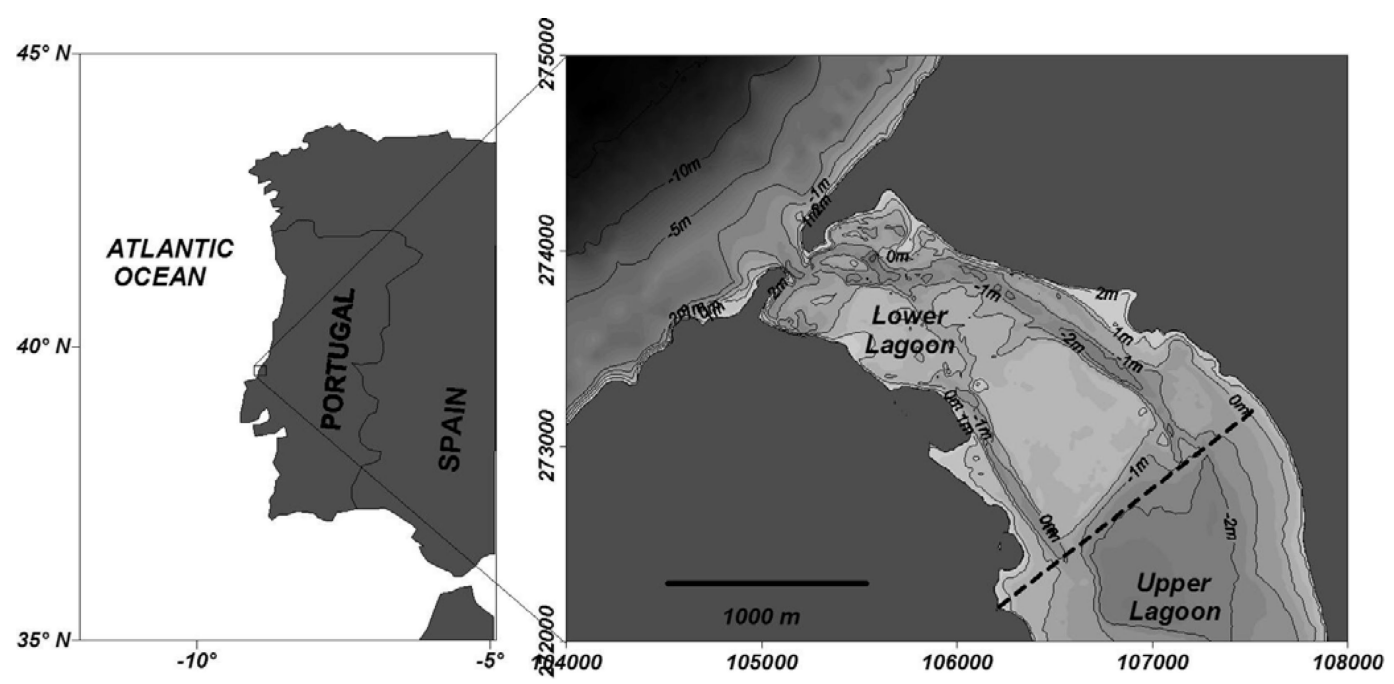

Figure 1. General location of the study area and bathymetry of the Óbidos lagoon in July 2001, which is the initial bathymetry for numerical simulations.

system MORSYS2D is presented in the third section, with a detailed description of several improvements since the first version of Fortunato and Oliveira (2004). The sensitivity analysis of this modeling system will be then investigated in the fourth section, through the influence of the model settings on the development of the tidal inlet. The pertinence of model predictions comparing to classical theoretical knowledge on tidal inlet stability is also discussed in this last section.

\section{THE STUDY AREA}

The Óbidos lagoon is a small coastal system located on the western Portuguese coast (Figure 1). This area is subjected to semi-diurnal tides, ranging from $1 \mathrm{~m}$ to $4 \mathrm{~m}$ (meso-tidal). The oceanic wave regime is very energetic during the winter months, during which waves of significant height exceeding $6 \mathrm{~m}$ were already recorded in front of the inlet (Oliveira et al., 2006).

The lower lagoon is characterized by a tidal inlet connected to a web of narrow channels and large sand banks, where velocities are very large. The upper lagoon has small velocities and muddy bottom (Oliveira et al., 2006) and thus this study will focus on the lower lagoon (figure 1). The morphological evolution of the lower lagoon is driven essentially by tidal currents while the oceanic part of the tidal inlet is also influenced by waves. The lower lagoon channels evolve rapidly, with displacements of the channels on the order of ten meters in a single tidal cycle.

Aerial photos of the last decades show that the position and number of channels and sand banks is in

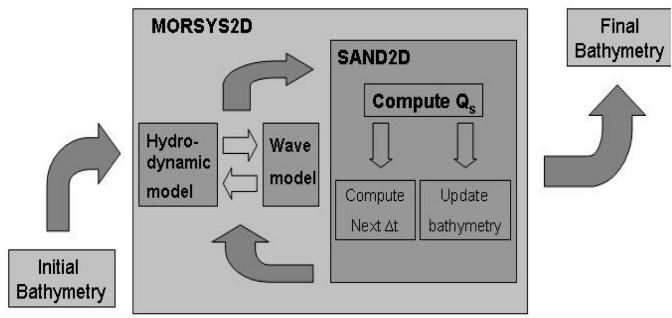

Figure 2. Diagram of MORSYS2D procedure.

permanent mutation, with meanders that form, grow and disappear in a few months (Oliveira et al., 2006). In this study, the bathymetry measured in July 2001 will be considered as the initial condition (Figure 1).

\section{THE MORPHODYNAMIC MODELING SYSTEM MORSYS2D}

\subsection{Model description and latest developments}

The modeling system MORSYS2D simulates the non-cohesive sediment dynamics in estuaries, tidal inlets and coastal regions, driven by tides, wind, river flows and waves (Figure 2). It integrates hydrodynamic models (ADCIRC, Luettich et al. 1991 - www.adcirc.org, and ELCIRC, Zhang et al. 2004 - www.ccalmr.ogi.edu/CORIE/modeling/elcirc/ index.html), a wave model (REF/DIF1, Kirby and Dalrymple, 1994 - http://chinacat.coastal.udel.edu/ programs/ refdif/refdif.html), a sand transport model and a bottom update model (SAND2D, Fortunato and 
Oliveira 2004). The system consists of a C-Shell script that runs independent models, manages the transfer of information between them and performs control checks.

The bottom update model simulates sand transport due to waves and currents using semi-empirical formulae and computes the resulting bed changes through the Exner equation (Fortunato and Oliveira, 2004). This equation is solved with a node-centered finite volume technique based on an unstructured triangular grid:

$\Delta h^{i}=\frac{1}{1-\lambda} \nabla Q^{i}$

where $Q$ is the sediment flux integrated over the morphological time step, $\lambda$ is the porosity and $h$ is depth relative to the mean water level.

In the original formulation, velocities and water levels were fed into SAND2D in the frequency domain (i.e., through tidal amplitudes and phases, rather than time series). In order to compute the harmonic constants, a hydrodynamic simulation for at least a full tidal cycle was required for each morphological step, independently of the time step. While this method has revealed to be efficient for slowly evolving systems, its application to the very dynamic Óbidos lagoon required the use of the morphological factor method (Roelvink, 2006) with morphological factors well below unity (typically 0.1 , Fortunato and Oliveira, 2007) to prevent large Courant numbers and subsequent numerical oscillations. Besides being very time-consuming, this method implied to use a representative tide (M2 only), which could be problematic when trying to reproduce natural behavior of a coastal system. Finally, Oliveira et al. (2007) showed that solving eq. (1) with tidally-averaged fluxes was inadequate in areas where the tidal excursion is larger than the spatial scale of variability of tidal hydrodynamics.

Hence, it was decided to modify the initial code by feeding SAND2D with hydrodynamic results in the time domain. The stability of the system depends on the maximum Courant number $C u$ at each morphodynamic time step, since numerical oscillations tend to appear for values significantly larger than 1 :

$C u \approx \frac{b \cdot q_{s} \cdot \Delta t}{h \Delta x}$

where $q_{s}$ is the sand flux over the element, $h$ is the water depth, $\Delta x$ is the element size, $\Delta t$ the morphodynamic time step and $b$ the velocity power in the transport formulae (typically between 3 and 5, depending on the specific formulation). Using a constant time step $\Delta t$, maximum values of $C u$ vary over more than three orders of magnitude within a tidal cycle, thereby imposing very small time steps. To improve efficiency, an adaptative time step was implemented, aiming at constant $\mathrm{Cu}$. The $\mathrm{Cu}$ at the time step $\mathrm{n}+1$ is estimated from the previous $\mathrm{Cu}$, using a log-linear extrapolation:

$C u_{n+1}^{*}=\exp \left[2 \cdot \log \left(C u_{n}\right)-\log \left(C u_{n-1}\right)\right]$

Then the predicted time step is defined as:

$\Delta t_{n / n+1}^{*}=\frac{\Delta t_{n-1 / n}}{C u_{n+1}^{*}}$

To avoid oscillations of the predicted $\Delta t$, a relaxation factor is used, according to:

$\Delta t_{n / n+1}=\alpha \cdot \Delta t_{n / n+1}^{*}+(1-\alpha) \cdot \Delta t_{n-1 / n}$

Where $\alpha$ is a user-specified constant typically between 0.6 to 0.9 . The implementation of this adaptative timestep leads to $\Delta t$ values of about 5 minutes when sand fluxes are maximum (typically between 1 and 2 hours before and after low tide) and 45 minutes when sand fluxes are minimum (around high and low tide).

\subsection{Simulation settings and analysis strategy}

MORSYS2D simulations were conducted for 90 days (180 tidal cycles), starting from the July 2001 bathymetry (figure 1), after a repositioning and dredging of the mouth (Fortunato and Oliveira, 2007b). These simulations were forced by tides alone, ignoring river flow inputs (which are negligible in the absence of floods) and wave action (which is not the dominant process during the summer months). Boundary conditions for the hydrodynamic model were taken from the regional tidal model of Fortunato et al. (2002).

Since bathymetric data could not be collected within the surf zone during the hydrographic surveys, the morphodynamic simulations started without ebb delta at the tidal inlet. Result analyses were focused on the inlet mouth area, where mesh size was refined up to $10 \mathrm{~m}$. In addition to qualitative observations, the sensitivity analysis of the model was performed through the temporal evolution of two key parameters in tidal inlet dynamics: the inlet cross section (O'Brien, 1931; Jarrett, 1976; FitzGerald, 1996) and the volume of the ebb delta (Walton and Adams, 1976; FitzGerald, 1996). Three parameters were tested: (1) the sediment grain size; (2) the empirical transport formula; (3) the forcing tide (representative/real)(Table 1).

\section{RESULTS AND DISCUSSION}

\subsection{Influence of sediment grain size on the Óbidos Inlet development}

Sediment grain size around the inlet mouth typically ranges from 0.5 to $0.6 \mathrm{~mm}$ but then decrease landward and seaward (Oliveira et al., 2006). The influence of sediment grain size on the inlet development was 
Table 1. Setup of sensitivity analysis simulations. Abreviations for transport formulae are the following: A.W./Acker \& White (1973); V.R./Van Rijn (1984); E.H./Engelund \& Hansen (1967); K.K./Karim \& Kennedy (1990).

\begin{tabular}{llll}
\hline Run & $\begin{array}{l}\text { Sediment Grain } \\
\text { size }(\mathrm{m})\end{array}$ & $\begin{array}{l}\text { Transport } \\
\text { formula }\end{array}$ & Forcing tide \\
\hline 1 & 0.0007 & A.W. & Repres. \\
2 & 0.0006 & A.W. & Repres. \\
3 & 0.0005 & A.W. & Repres. \\
4 & 0.0004 & A.W. & Repres. \\
5 & 0.0006 & A.W. & Real \\
6 & 0.0006 & V.R. & Repres. \\
7 & 0.0006 & E.H. & Repres. \\
8 & 0.0006 & K.K. & Repres. \\
\hline
\end{tabular}

tested by running simulations with identical settings, except for grain size $\left(\mathrm{d}_{50}\right)$ which ranged from $0.7 \mathrm{~mm}$ to $0.4 \mathrm{~mm}$ (runs $1-4$ ).

The temporal evolution of the inlet cross section firstly shows an enlargement of the inlet throat, which is faster when sediments are finer (figure 3). Nevertheless, after three month of simulation, inlet crosssections converge towards a value of about $330 \mathrm{~m}^{2}$. This behavior corroborates the analytical work of Kraus (1998), later refined by Hugues (2002), which suggest a minor influence of sediment grain size on inlet cross sections.

The development of the ebb delta is also faster with finer sediments, while the converging tendency observed for the cross-section is less marked, which suggest that finer sediments would produce a larger ebb-delta.

\subsection{Influence of the forcing tide on Óbidos Inlet development}

Previous morphodynamic simulations at Óbidos lagoon were forced by a single tidal constituent (M2) and its major harmonics (Z0, M4 and M6), resulting in a tidal range of about $2 \mathrm{~m}$ outside the lagoon, which can be assimilated as a representative tide. In order to test the influence of this representative tide, run 5 was forced by a tide represented by the 12 main harmonic constituents.

The temporal evolution of the inlet cross section displays a more irregular behavior with the real tide. Its evolution is characterized by a 15 day-periodicity, with fast increase during spring tides, followed by small decreases during neaps (figure 4). This behavior is coherent with the observations of FitzGerald (1996), who reported cross-section variations at Price Inlet (U.S.A.) by the order of $7 \%$ within a single spring tidal cycle. After three months of evolution, no convergence between the two curves can be observed and the inlet cross-section with the real tide is significantly larger. This latter behavior agrees with the relation of O'Brien
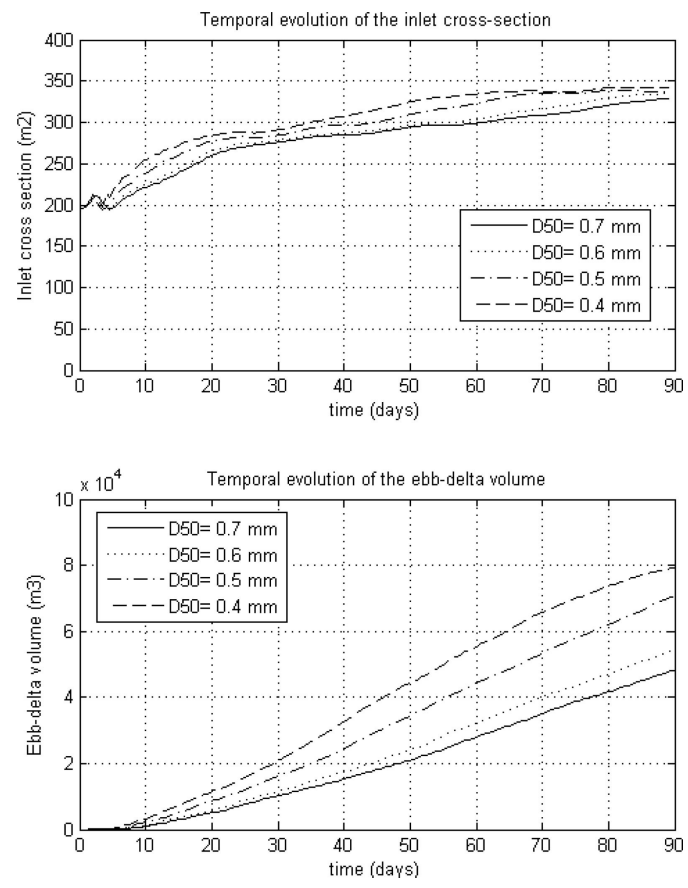

Figure 3. Temporal evolutions of the inlet cross-section and ebb-delta volume as a function of sediment grain-size.
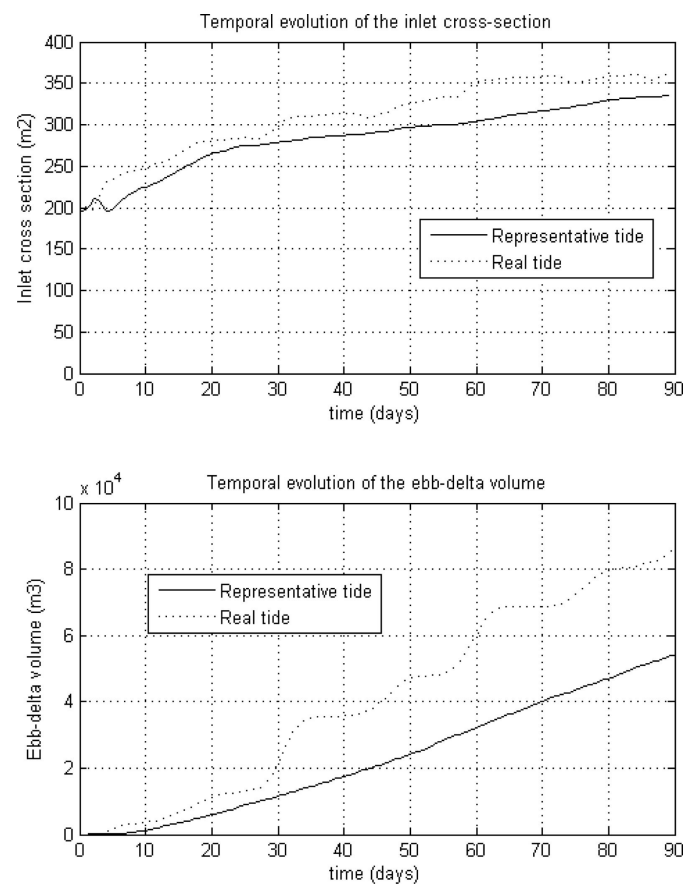

Figure 4. Temporal evolutions of the inlet cross-section and ebb-delta volume depending on the forcing tide. 
(1931, 1969), later refined by Jarett (1976) and others, which states that the inlet cross-section is in equilibrium with the spring tidal prism, larger in the case of the real tide.

The ebb-delta also experiences an irregular development when the simulation is forced with a real tide. Its evolution also seems to follow a 15-day cycle, where a strong accretion occurs during spring tides and a very weak accretion on neap tides (figure 4). After three months of simulation, the ebb delta produced by the real tide is about $50 \%$ larger than the ebb delta originating from the representative tide. This difference is in good agreement with the relation proposed by Walton and Adams (1976), which states that the ebb-delta volume is a growing function of the spring tidal prism, larger in the case of the real tide.

\subsection{Influence of the empirical formula on Óbidos Inlet development}

The sensitivity of empirical transport formulas on transport predictions has already been addressed by comparison with field data (Camenen \& Larroudé, 2003) or using Monte Carlo approaches (Pinto et al., 2006). The purpose of this section is the test of the influence of the transport formulas on the development of the Óbidos Inlet. Runs 2, 6, 7 and 8 only differ by the empirical formula used to compute fluxes.

The temporal evolution of the inlet cross-section display different behaviors, depending on the formula used to compute sand fluxes. Whereas evolutions are comparable using the Ackers \& White (1973), the Engelund \& Hansen (1967) and the Karim \& Kennedy (1990) formulas, the van Rijn (1984) formula seems to induce faster changes. After three months of simulation, inlet cross-sections converge toward a value of about $340 \mathrm{~m}^{2}$, except for the van Rijn (1984) formula, which induces a cross-section significantly larger.

The development of the ebb-delta also displays strong differences depending on the formula used to compute sand fluxes. Whereas the Ackers \& White (1973), the Engelund \& Hansen (1967) and the Karim \& Kennedy (1990) formulas generate comparable evolutions, the van Rijn formula (1984) produces an almost three-time larger ebb-delta.

The excessive sand fluxes and very fast changes induced by the van Rijn formula (1984) corroborates the conclusions of Pinto et al. (2006), who noticed that this formula was very sensitive to basic physical properties.

\subsection{Overall validity of model predictions}

For the different simulations, the inlet throat experiences a fast and important enlargement, which with a 50 to $65 \%$ increase of the inlet cross-section relative to the initial bathymetry. After three months of simulations, the inlet throat seems to stabilize, suggesting that
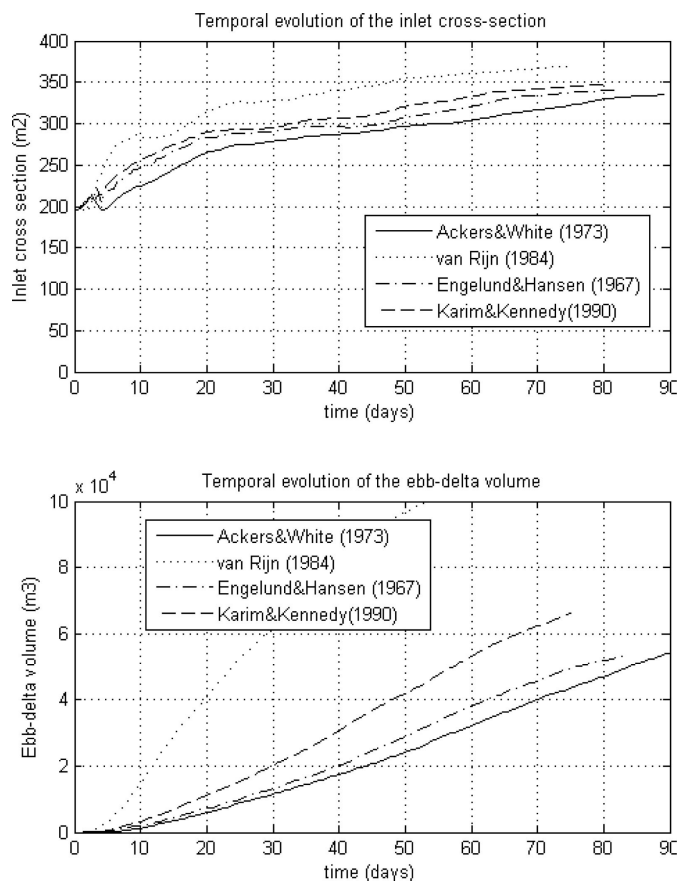

Figure 5. Temporal evolutions of the inlet cross-section and of the ebb-delta volume depending on the empirical formula used to compute sand fluxes.

a new equilibrium is reached. This evolution could be due to the absence of wave forcing, which promote the development of hydraulically-efficient channels promoting tidal propagation.

Equilibrium also seems to be reached in the whole inlet system, since morphological changes of the tidal deltas and channels appear very weak during the last month of simulation. Finally, after three months of simulations, inlet morphologies are noticeably comparable for the 8 simulations. Actually, from a qualitative viewpoint, figure 6 shows: (1) strong similarities in the shape of the tidal deltas, (2) strong similarities in the location and morphology of the channels and (3) the presence of a secondary flood channel, which develops northward of the ebb-delta. These similarities suggest that the model sensitivity discussed in the previous sections (sediment grain size, transport formulae and forcing tide) rather affects the rapidity of morphological changes and specific quantitative parameters. Given these results and considering the whole inlet system, the numerical model can claim a predictive skill on the time scale of the months.

\section{CONCLUSIONS}

The MORSYS2D morphodynamic modeling system was improved and applied to the rapidly evolving 

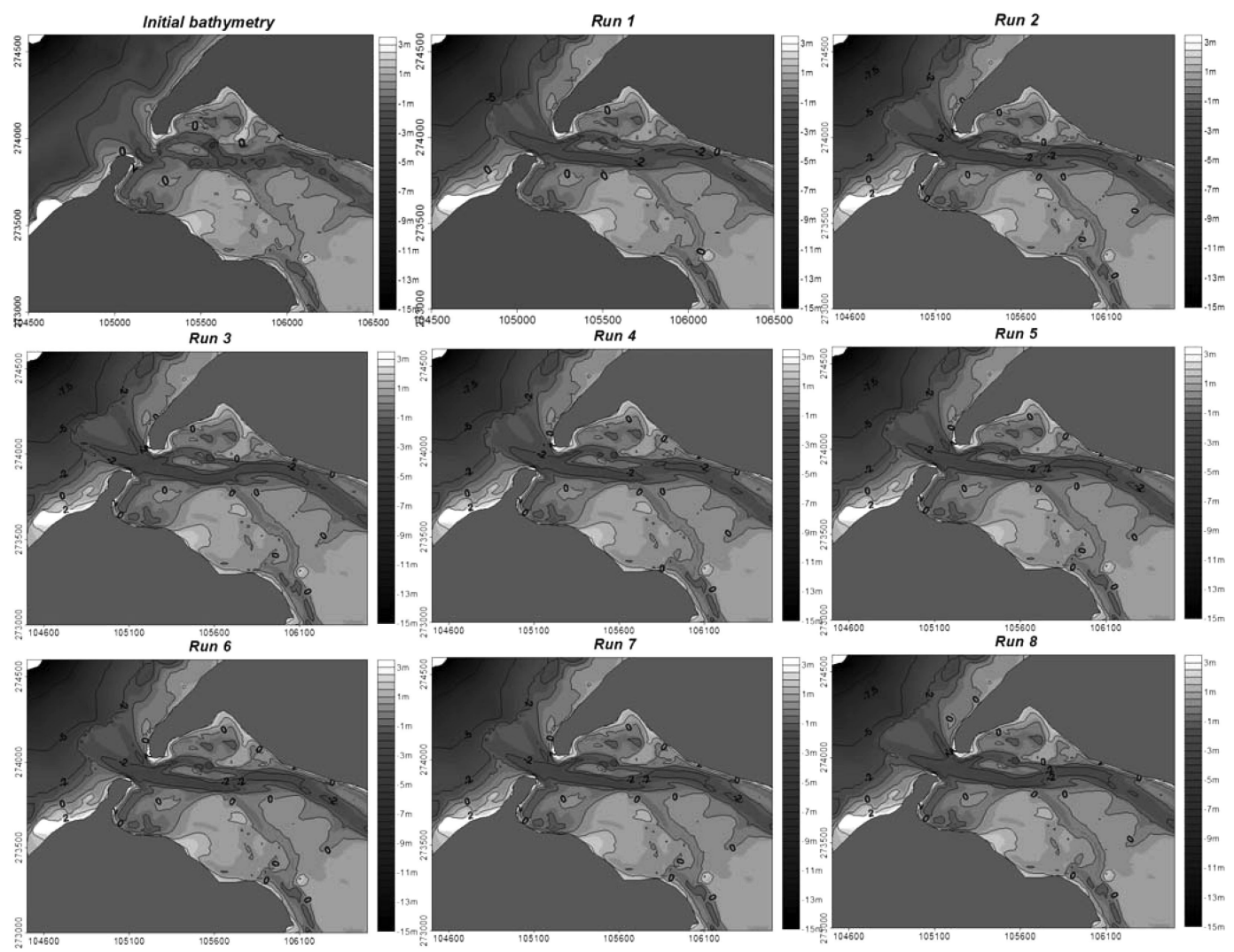

Figure 6. Final bathymetries obtained from morphodynamic simulations of Óbidos Inlet after 3 months, permitting to observe a general good agreement whatever are the input parameters.

Óbidos Lagoon. Sensitivity analyses were performed through the temporal evolution of the inlet crosssection and the ebb-delta development and suggest the following remarks:

- Sediment grain size mostly affects the rapidity of morphological changes and the time required for equilibrium to be reached.

- Forcing the model with a real tide rather than a representative tide produces faster changes, 15-day cyclic evolutions and larger cross-sections and ebb delta volume.

- The sediment grain size and the choice of the empirical formula mostly affect the rapidity of morphological changes, except for the van Rijn formula (1984), which seems to generate excessive sand fluxes.

Nevertheless, when looking to the overall inlet system after three months of simulations, noticeable morphological similarities can be observed, which suggest an overall reliability of the modeling system on the time scale of the months. Further works have to be conducted, such as the analysis of the wave effects, simulations on periods of time larger than three months and validation of the results by comparison with repetitive bathymetric surveys.

\section{ACKNOWLEDGEMENTS}

The first author was funded by the European Commission. Through his Marie Curie postdoctoral fellowship (project IMMATIE-041171). This work was partially funded by the Fundação para a Ciência e a Tecnologia, Programa Operacional "Ciência, Tecnologia, Inovação", and FEDER, projects SATUrN: Sand Transport in Surface Waters: an Uncertainty Analysis, and EMERA: Estudo da Embocadura da Ria de Aveiro, and through LNEC's Project "Evolução a longo prazo da morfologia estuarina e lagunar" and "Morphodynamica de embocaduras". The authors are indebted to Prof. A.M. Baptista and Y. Zhang for the model ELCIRC and the software XMVIS. 


\section{REFERENCES}

Ackers P. \& White, W.R. 1973. Sediment transport: new approach and analysis, Journal of the Hydraulics Division, ASCE 99 (11), 2041-2060.

Callaghan, D.P., Saint-Cast, F., Nielsen, P. and Baldock, T.E. 2006. Numerical solutions of the sediment conservation law; a review and improved formulation for coastal morphological modeling, Coastal Engineering, 53, 557-571.

Camenen, B. and Larroudé, P., 2003. Comparison of sediment transport formulae for the coastal environment. Coastal Engineering 48, 111-132.

Cayocca, F., 2001. Long-term morphological modeling of a tidal inlet: the Arcachon Basin, France, Coastal Engineering, 42(2) 115-142.

Engelund, F. and Hansen, E., 1967. A Monograph on Sediment Transport in Alluvial Streams. Teknisk Forlag, Technical University of Denamark, Ostervolgade 10, Copenhagen, Denmark.

FitzGerald, D.M., 1996. Geomorphic variability and morphodynamics and sedimentologic controls on tidal inlets. Journal of Coastal Research, S.I. 23, 47-71.

Fortunato, A.B., 2007. Accuracy of sediment flux computations in tidally-driven simulations, Journal of Waterways, Ports, Coastal and Ocean Engineering, in press.

Fortunato, A.B. \& Oliveira, A. 2004. A modeling system for tidally driven long-term morphodynamics, Journal of Hydraulic Research, 42(4), 426-434.

Fortunato, A.B. \& Oliveira, A. 2007a. Improving the Stability of a morphodynamic modeling system, Journal of Coastal Research, SI50, in press.

Fortunato, A.B. \& Oliveira, A. 2007b. Case Study: Improving the Stability of the Óbidos Lagoon Inlet, Journal of Hydraulic Engineering, 133(7).

Fortunato, A.B., Pinto, L., Oliveira, A. and Ferreira J.S. 2002. Tidally-generated shelf waves off the Western Iberian coast, Continental Shelf Research, 22(14), 1935-1950.

Hugues, S.A., 2002. Equilibrium Cross Sectional area at tidal inlets. Journal of coastal research 18, 160-174.

Jarrett, J.T., 1976. Tidal prism-inlet area relationships. GITI Report No. 3, US Army Corps of Engineers, Waterways Experiment Station, Vicksburg, MS, 54 pp.

Jonhson H.K. \& Ziserman, J.A., 2002. Controlling spatial oscillations in bed level update schemes, Coastal Engineering, 46(2), 109-126.

Karim, M.F. \& Kennedy, J.F., 1990. Menu of couple velocity and sediment discharge relation for rivers. Journal of Hydraulic Engineering, 116(8) 978-996.

Kirby, J.T. \& Dalrymple, R.A., 1994. Combined Refraction Diffraction model REF/DIF1-version2.5. Documentation and User's manual. CACR Report 94-22.
Kraus, N.C., 1998. Inlet Cross-section area calculated by process-based model. Proc. Of the 26th International Coastal Engineering conference, New York, Vol. 3, 3265 3278.

Luettich, R.A., Westerink, J.J. and Sheffner, N.W., 1991. ADCIRC: An advanced three-dimensional model for shelves, coasts and estuaries. Report 1: theory and methodology of ADCIRC-2DDI and ADCIRC-3DL, Department of the Army, US Army Corps of Engineers.

O'Brien, M.P., 1931. Estuary tidal prisms related to entrance areas. Civ. Eng. 1, 738-739.

O'Brien, M.P., 1969. Equilibrium flow areas of inlets on sandy coasts. J. Waterw. Harb, Coast. Eng., ASCE 95 (1969), 43-55.

Oliveira, A., Fortunato, A.B., 2002. Towards an oscillationfree, mass conservative, Eulerian-Lagrangian transport model, Journal of Computational Physics, 183(1) 142164.

Oliveira, A., Fortunato, A.B., and Sancho, F.E.P., 2005. Morphodynamic modeling of the Óbidos lagoon, Proc. 29th International Conference on Coastal Engineering (ASCE), vol.3, pp. 2506-2518.

Oliveira, A., Fortunato, A.B., and Rego, J., 2006. Effect of Morphological changes on the hydrodynamics and flushing properties of the Óbidos Lagoon, Continental Shelf Research, 26(8), 917-942.

Oliveira, A., Fortunato, A.B., and Dias, J.M., 2007. Numerical Modeling of the Aveiro Inlet Dynamics Proc. 30th International Conference on Coastal Engineering (ASCE), in press.

Pinto, L., Fortunato, A.B. and Freire, P., 2006. Sensitivity analysis of non-cohesive sediment transport formulae. Continental Shelf Research 26(15), 1826-1839.

Roelvink, J.A., 2006. Coastal morphodynamic evolution techniques, Coastal Engineering, 53(2-3), 277-287.

Thanguy, J.M., Zhang, B.N. and Hamm, L., 1993. A new LaxWendroff algorithm to solve the bed continuity equation with slope effect, In: SPAULDING et al. (Eds.), Estuarine and Coastal Modeling III, ASCE, 134-148.

Van Rijn, L.C., 1984. Sediment transport, part II: suspended load transport, Journal of Hydraulic Engineering 110(11), 1613-1641.

Walton, T.L. and Adams, W.D., 1976. Capacity of inlet outer bars to store sand. In: Fifteenth Coastal Engineering Conference Proc., ASCE, Honolulu, HI (1976), 1919-1937.

Zhang, Y., Baptista, A.M., Myers, E.P., 2004. A crossscale model for 3D baroclinic circulation in estuaryplume-shelf systems: I. Formulation and skill assessment, Continental Shelf Research, 24(18), 2187-2214. 
